\title{
SHARP GAUTSCHI INEQUALITY FOR PARAMETER $0<p<1$ WITH APPLICATIONS
}

\section{Zhen-Hang YAng, Wen Zhang And Yu-Ming Chu}

Abstract. In the article, we present the best possible parameters $a, b$ on the interval $(0, \infty)$ such that the Gautschi double inequality $\left[\left(x^{p}+a\right)^{1 / p}-x\right] / a<e^{x^{p}} \int_{x}^{\infty} e^{-t^{p}} d t<\left[\left(x^{p}+b\right)^{1 / p}-x\right] / b$ holds for all $x>0$ and $p \in(0,1)$. As applications, we find new bounds for the incomplete gamma function $\Gamma(a, x)=\int_{x}^{\infty} t^{a-1} e^{-t} d t$.

Mathematics subject classification (2010): 33B20, 26D07, 26D15.

Keywords and phrases: Incomplete gamma function, gamma function, psi function.

\section{REFERENCES}

[1] H. Alzer, On some inequalities for the incomplete gamma function, Math. Comp. 66, (218) (1997), $771-778$

[2] H. Alzer AND Á. BARICZ, Functional inequalities for the incomplete gamma function, J. Math. Anal. Appl. 385, (1) (2013), 167-178.

[3] G. D. Anderson, M. K. Vamanamurthy and M. Vuorinen, Conformal Invariants, Inequalities, and Quasiconformal Maps, John Wiley \& Sons, New York, (1997).

[4] J. M. BORWEIN AND O. Y. CHAN, Uniform bounds for the complementary incomplete gamma function, Math. Inequal. Appl. 12, (1) (2009), 115-121.

[5] Y.-M. CHU, X.-M. ZHANG AND Z.-H. ZHANG, The geometric convexity of a function involving gamma function with applications, Commun. Korean Math. Soc. 25, (3) (2010), 373-383.

[6] Á. ElBERT AND A. LAFORGIA, An inequality for the product of two integrals related to the incomplete gamma function, J. Inequal. Appl. 5, (1) (2000), 39-51.

[7] G. FrankLin MONTGOMERY, On the transmission error function for meteor-burst communication, Proc. IRE. 46, (1958), 1423-1424.

[8] W. GAUTSCHI, Some elementary inequalities relating to the gamma and incomplete gamma function, J. Math. Phys. 38, (1959/60), 77-81.

[9] B. GuHA, Expansion of incomplete gamma function in terms of Jacobi polynomials, Indian J. Pure Appl. Math. 12, (8) (1981), 990-993.

[10] H.-L. GUPTA, An integral equation involving incomplete gamma function as the kernel, Indian J. Pure Appl. Math. 7, (12) (1976), 1361-1366.

[11] S. S. GUPTA AND M. N. WAKNIS, A system of inequalities for the incomplete gamma function and the normal integral, Ann. Math. Statist. 36, (1965), 139-149.

[12] A. Guthmann, Asymptotische Entwicklungen für unvollständige Gammafunktionen, Fourm Math. 3, (2) (1991), 105-141.

[13] M. E. H. ISMALL AND A. LAFORGIA, Functional inequalities for incomplete gamma and related functions, Math. Inequal. Appl. 9, (2) (2006), 299-302.

[14] R. N. Kalia And S. KeIth, Fractional calculus and expansions of incomplete gamma functions, Appl. Math. Lett. 3, (1) (1990), 19-21.

[15] S. H. KHAMIs, Incomplete gamma functions expansions of statistical distribution functions, Bull. Inst. Internat. Statist. 37, (3) (1960), 385-396.

[16] W. F. KiBBLE, A Bessel function in terms of incomplete Gamma functions, J. Indian Math. Soc. 3, (1) (1939), 271-294. 
[17] Y. Komatu, Elementary inequalities for Mills' ratio, Rep. Statist. Appl. Res. Un. Jap. Sci. Engrs. 4, (1955), 69-70.

[18] A. LAFORgIA AND P. NATALini, Supplements to known monotonicity results and inequalities for the gamma and incomplete gamma function, J. Inequal. Appl. 2006, Article ID 48727 (2006), 8 pages.

[19] Y. L. LUKE, On the error in the Pade approximants for a form of the incomplete gamma function including the exponential function, SIAM J. Math. Anal. 6, (5) (1975), 829-839.

[20] B. A. MAMEDOV, Analytical evaluation of the thermionic emission probability for semiconductorinsulator interfaces using incomplete gammam functions, Appl. Math. Comput. 217, (13) (2011), $6282-6285$.

[21] M. R. MURTY AND E. SAHA, Transcendental values of the incomplete gamma function and related questions, Arch. Math. 105, (3) (2015), 271-283.

[22] P. Natalini And B. Palumbo, Inequalities for the incomplete gamma function, Math. Inequal. Appl. 3, (1) (2000), 69-77.

[23] E. Neuman, Inequalities and bounds for the incomplete gamma function, Results Math. 63, (3-4) (2013), 1209-1214.

[24] R. B. PARIS, Error bounds for the uniform asymptotic expansion of the incomplete gamma function, J. Comput. Appl. Math. 147, (1) (2002), 215-231.

[25] R. B. PARIS, A uniform asymptotic expansion for the incomplete gamma function, J. Comput. Appl. Math. 148, (2) (2002), 323-339.

[26] H. O. Pollak, A remark on "Elementary inequalities for Mills' ratio" by Yûsaku Komatu, Rep. Statist. Appl. Res. Un. Jap. Sci. Engrs. 4, (1956), 110-110.

[27] F. QI, Monotonicity results and inequalities for the gamma and incomplete gamma functions, Math. Inequal. Appl. 5, (1) (2002), 61-67.

[28] F. QI AND S.-L. GUO, Inequalities for the incomplete gamma and related functions, Math. Inequal. Appl. 2, (1) (1999), 47-53.

[29] F. QI AND J.-Q. MEI, Some inequalities of the incomplete gamma and related functions, Z. Anal. Anwendungen 18, (3) (1999), 793-799.

[30] W. O. Schumann, Elektrische Durchbruchfeldstäke von Gasen, Springer, Berlin, 1923.

[31] N. M. Temme, The asymptotic expansion of the incomplete gamma functions, SIAM J. Math. Anal. 10, (4) (1979), 757-766.

[32] M.-K. WANG AND Y.-M. ChU, Refinements of transformation inequalities for zero-balanced hypergeometric functions, Acta Math. Sci. 37B, (3) (2017), 607-622.

[33] M.-K. WANG, Y.-M. CHU AND S.-L. QIU, Sharp bounds for generalized elliptic integrals of the first kind, J. Math. Anal. Appl. 429, (2) (2015), 744-757.

[34] M.-K. WANG, Y.-M. ChU AND Y.-Q. Song, Asymptotical formulas for Gaussian and generalized hypergeometric functions, Appl. Math. Comput. 276, (2016), 44-60.

[35] M.-K. WANG, Y.-M. Li AND Y.-M. CHU, Inequalities and infinite product formula for Ramanujan generalized modular equation function, Ramanujan J. DOI 10.1007/s11139-017-9888-3.

[36] K. YAMAGATA, A contribution to the theory of non-isothermal laminar flow of fluids inside a straight tube of circular cross section, Mem. Fac. Engineering, Kyushu Imp. Univ. 8, (1940), 365-449.

[37] Z.-H. YANG, A new way to prove L'Hospital Monotone Rules with applications, arXiv:1409.6408 [math.CA], available online at http://arxiv.org/pdf/1409.6408v1.pdf.

[38] Z.-H. Yang AND Y.-M. ChU, Asymptotic forumlas for gamma function with applications, Appl. Math. Comput. 270, (2015), 665-680.

[39] Z.-H. YANG, Y.-M. CHU AND M.-K. WANG, Monotonicity criterion for the quotient of power series with applications, J. Math. Anal. Appl. 428, (1) (2015), 587-604.

[40] Z.-H. YANG, W. ZHANG AND Y.-M. CHU, Monotonicity and inequalities involving the incomplete gamma function, J. Inequal. Appl. 2016, Article 221 (2016), 10 pages.

[41] Z.-H. YANG, W. ZHANG AND Y.-M. CHU, Monotonicity of the incomplete gamma function with applications, J. Inequal. Appl. 2016, Article 251 (2016), 10 pages.

[42] X.-M. Zhang And Y.-M. ChU, A double inequality for gamma function, J. Inequal. Appl. 2009, Article ID 503782 (2009), 7 pages.

[43] T.-H. ZhaO AND Y.-M. CHU, A class of logarithmicall complete monotonic functions associated with a gamma function, J. Inequal. Appl. 2010, Article ID 392431 (2010), 11 pages.

[44] T.-H. ZhaO, Y.-M. ChU AND Y.-P. JIANG, Monotonic and logarithmically convex properties of a function involving gamma functions, J. Inequal. Appl. 2009, Article ID 728612 (2009), 13 pages. 
[45] T.-H. ZHAO, Y.-M. CHU AND H. WANG, Logarithmically complete monotonicity properties relating to the gamma function, Abstr. Appl. Anal. 2011, Article ID 896483 (2011), 13 pages. 